\title{
Pathogenesis of Ventricular Arrhythmias and Its Effect on Long-Term Prognosis in Patients With Takotsubo Cardiomyopathy
}

Julio A. Pena Escobar ${ }^{1}$, Myat Aung ${ }^{2}$, Saba Amin ${ }^{2}$, Azouba Gulraiz ${ }^{2}$, Fenil R. Gandhi ${ }^{2}$, Bilal Haider Malik 1

1. Internal Medicine, California Institute of Behavioral Neurosciences \& Psychology, Fairfield, USA 2. Medicine, California Institute of Behavioral Neurosciences \& Psychology, Fairfield, USA

Corresponding author: Julio A. Pena Escobar, julio.amilcar22@gmail.com

\begin{abstract}
Takotsubo cardiomyopathy (TTC), also known as broken heart syndrome, stress cardiomyopathy (SCM), or apical ballooning syndrome, is a non-ischemic cardiac disease with an initial clinical presentation that is very similar to acute coronary syndrome (ACS). Ventricular arrhythmias (VAs) contribute significantly to an increase in the rates of death in patients with TTC, especially during the acute phase, in which patients with TTC are more susceptible to develop life-threatening arrhythmias (LTA) such as ventricular tachycardia (VT), ventricular fibrillation (VF), torsades de pointes (TdP), and sudden cardiac death (SCD). However, the pathophysiology of TTC and how VA occurs are still a mystery. We aim to review previous literature and discuss the possible mechanisms of VA in TTC patients.
\end{abstract}

VA usually complicates the acute phase of the disease and worsens the long-term prognosis. Alterations of repolarization (negative T wave, prolonged QTc) indicate a high risk of arrhythmic events (TdP, VT, VF, and SCD). Catecholamine effect on myocardial cells and myocardial edema can create a substrate for the development of VA. Some of the most commonly proposed mechanisms for the development of VA in patients with TTC are coronary vasospasm, myocardial stunning due to catecholamines, re-entry, and triggered activity. Further prospective studies, including a more significant number of patients, are required to understand the disease's pathophysiology better and improve LTA management in patients with TTC.

Received 09/10/2020 Review began 09/18/2020 Review ended 10/25/2020 Published 10/26/2020

(c) Copyright 2020 Pena Escobar et al. This is an open access article distributed under the terms of the Creative Commons Attribution License CC-BY 4.0., which permits unrestricted use, distribution, and reproduction in any medium, provided the original author and source are credited.
Categories: Cardiology, Internal Medicine

Keywords: ventricular arrhythmias, takotsubo cardiomyopathy, stress cardiomyopathy, torsades de pointes (tdp), cardiac arrhythmia

\section{Introduction And Background}

Takotsubo cardiomyopathy (TTC), also known as broken heart syndrome, stress cardiomyopathy (SCM), or apical ballooning syndrome, is a type of non-ischemic cardiac disease characterized by an acute dysfunction of the myocardial tissue primarily affecting the left ventricle. However, the right ventricle can also be affected [1]. TTC received its name from the Japanese word "takotsubo" due to the distinctive appearance of the left ventricle (LV) resembling a jar used by Japanese fishermen to capture octopuses. The initial clinical presentation of TTC is very similar to acute coronary syndrome (ACS). Similar patterns of cardiac enzymes and changes on the electrocardiograph (ECG) are almost identical between them. The only separating factor is the absence of coronary artery disease or stenosis in TTC [2]. The most striking feature of TTC is a transient abnormality of the left ventricular motion, which results in the ballooning of the LV during systole. This ventricular dysfunction is only transitory in most cases, with a return to normal LV function within a few days or weeks [3]. The latter fact led to the belief that the disease carried an excellent prognosis. However, after years of study and many reported cases, we now know TTC prognosis is worse than what we initially expected.

TTC currently represents $1 \%-3 \%[4,5]$ of all patients and 5\%-6\% [6] of women with clinical suspicion of ACS. The disease is more frequent in postmenopausal women ( 55 years and older) than in younger females and males. TTC is usually precipitated primarily by emotional and physical stressors; many cases could also occur without any of these stressful factors being present. The pathophysiological mechanism of TTC is very complex and, until these days, remains unclear. Multiple theories are trying to explain what has been described as multifactorial [7].

During the acute phase, patients with TTC are more susceptible to cardiovascular-related complications, including congestive heart failure (HF), ventricular arrhythmias (VAs), and cardiogenic shock [8-9]. A wide variety of arrhythmias are associated with TTC; the list includes life-threatening arrhythmias (LTA) such as ventricular tachycardia (VT), ventricular fibrillation (VF), prolongation of the QT interval leading to torsades de pointes (TdP), and, in the worst-case scenario, sudden cardiac death (SCD) [10]. Life-threatening ventricular arrhythmias (LTA) can occur during the acute phase of the disease, probably due to myocardial ischemia and catecholamines on the myocardium [11]. Ventricular arrhythmias contribute significantly to TTC mortality rates; however, the underlying VA mechanisms are still not well understood. Some of these mechanisms alter repolarization [12], re-entry, and abnormal automaticity [1]. However, their role 
provoking VA in TTC needs to be fully determined.

We plan to conduct a review article while collecting information from previously published reviews and relevant case reports to establish the relationship between TTC and VA. Moreover, we attempt to summarize the possible mechanisms leading to them and to describe the effect on the patient's long-term prognosis in TTC.

\section{Review}

Ventricular arrhythmic events associated with TTC come from a very long time. However, clinically relevant information was limited to only a few case reports or small observational studies, resulting in underestimating VA actual burden in patients with TTC [1]. During the acute phase, patients with TTC are more susceptible to develop VA, including VT, VF, QT interval prolongation leading to TdP, and, in the worse cases, SCD [10]. Ventricular arrhythmias contribute significantly to TTC mortality rates; however, the pathophysiological mechanisms leading to the development of these LTA are not well understood. That is why it is essential to summarize the possible arrhythmogenic mechanisms in TTC.

\section{Long QT syndrome and torsades de pointes}

ECG alterations are one of the TTC hallmarks, and one of the most significant changes is a prolongation of the QT interval, which usually develops in the first two days after the initial symptoms. A QTc greater than $500 \mathrm{~ms}$ is a significant risk factor for VA, particularly VF and TdP [9].

Ahn et al. [13] described a 78-year-old woman presenting with syncope after psychological stress. ECG findings on admission showed QTc measuring $580 \mathrm{~ms}$ and a heart rate of 40 beats per minute; on day two, QTc increased to $720 \mathrm{~ms}$, which led to developing TdP. She was treated with DC cardioversion and magnesium sulfate and received a dual-chamber pacemaker. After discharge three months later, her ECG was still positive for prolongation of QTc, measuring $552 \mathrm{~ms}$. Sasaki et al. [14] described a 22-year-old woman presenting with chest pain and syncope. The heart rate was 50/min. Initial ECG showed QTc of 730 $\mathrm{ms}$ with multifocal premature ventricular contractions (PVC) and development of TdP; then she received defibrillation, and QT normalized during hospitalization. Eleven months after discharge, she consulted for palpitations and chest discomfort, and her ECG showed QTc of $690 \mathrm{~ms}$. Family history was negative for cardiovascular disease, not genetically tested. El-Battrawy, Behnes, Borggrefe, and Akin [15] presented a 72year-old woman with angina pectoris one day after septoplasty; her initial QTc was $661 \mathrm{~ms}$. The genetic test found her to have a heterozygous type 1 mutation in KCNQ1. Five weeks after discharge, her QTc was $487 \mathrm{~ms}$ $[15]$.

Similarities exist across all these patients in terms of ECG findings and physical exam. According to the literature, they were predominantly women after menopause, and after a typical stressful factor, either emotional or physical (septoplasty).

\section{Ventricular tachycardia, ventricular fibrillation, and other ventricular arrhythmias}

Cakıcı, Cetin, Polat, and Su Ner described a 67-year-old female with dizziness and palpitations after emotional stress, who presented with episodes of VT on ECG. While QTc was $680 \mathrm{~ms}$ [16], TdP did not occur during monitoring. She received cardioversion because of hemodynamic compromise due to VT. On followup, her QTc was 400 ms. Demir, Babur Güler, Güler, Güneş, and Kızılırmak [17] described a 27-year-old healthy woman admitted for endoscopic sinus surgery. She developed VF during recovery from anesthesia, treated with defibrillation. No stress other than the surgical procedure was present.

Watanabe et al. described a 65-year-old man with dyspnea and no recorded stressful factors. ECG showed TdP-type VT, which was terminated by cardio-pulmonary resuscitation without defibrillation. QTc was 693 ms during the episode, and six months after discharge, it returned to the standard value [18]. Rotondi et al. studied a 65-year-old woman with syncope after emotional stress [19]. Her QTc was 671 ms on ECG. She presented an episode of VT six months prior. She was diagnosed with TTC six years earlier, also presented with VT. She also had a history of idiopathic dilated cardiomyopathy.

Wakatsuki, Asano, Mase, Kurata, and Suzuki [20] reported an 81-year-old man with a history of atrial fibrillation and end-stage renal disease on hemodialysis who was admitted for implantation of a pacemaker. Twenty-six hours after implantation, he developed QTc $539 \mathrm{~ms}$ with polymorphic VT, which resulted in VF requiring electrical shocks to terminate it. Ten days later, his ECG returned to normal. Caudron, Rey, and Dacher described a 34-year-old female with clinical symptoms of acute appendicitis. She developed hemodynamic collapse due to VF after induction of anesthesia requiring electrical shocks to resolve. Her ECG after the event showed reversal to baseline [21]. Sosnowska, Bąkowski, Woronowicz, and Wożakowska [11] published a case report of a 59-year-old female with sudden cardiac arrest due to VF posterior to family psychological stress. ECG record showed supraventricular extrasystoles and QTc $550 \mathrm{~ms}$ [11].

TTC tends to occur more frequently in postmenopausal women, especially after a recent stressful episode $[11,13,16,19]$; however, younger women are also at risk [14,17,21], and incidence in men continues to 
increase every day $[18,20]$. Emotional stress is arguably the most common trigger. However, physical stress such as surgical procedures, long-standing illness, septic shock, severe pain [15,17], or implantation of a pacemaker or defibrillator [20] is the usual cause. We observed prolongation of the QT in all the above patients; thus, this carries a higher chance of presenting life-threatening ventricular arrhythmias, particularly TdP and VF (Table 1$)$.

\begin{tabular}{|c|c|c|c|c|c|c|c|}
\hline Author & Age & Gender & $\begin{array}{l}\text { Stressful } \\
\text { precipitant present }\end{array}$ & Clinical presentation & ECG findings & QTc & $\begin{array}{l}\text { Progression } \\
\text { to VA }\end{array}$ \\
\hline $\begin{array}{l}\text { Sosnowska et } \\
\text { al. [11] }\end{array}$ & 59 & Female & Emotional & Cardiac arrest & $\begin{array}{l}\text { Supraventricular } \\
\text { extrasystoles }\end{array}$ & $\begin{array}{l}550 \\
\mathrm{~ms}\end{array}$ & VF \\
\hline Ahn et al. [13] & 18 & Female & Emotional & Syncope & $\begin{array}{l}\text { T wave inversion } \\
\text { precordial leads }\end{array}$ & $\begin{array}{l}580 \\
\mathrm{~ms}\end{array}$ & TdP \\
\hline $\begin{array}{l}\text { Sasaki et al. } \\
\text { [14] }\end{array}$ & 22 & Female & No & Syncope, chest pain & $\begin{array}{l}\text { Negative T waves II, aVL, } \\
\text { V2-6, PVC }\end{array}$ & $\begin{array}{l}730 \\
\mathrm{~ms}\end{array}$ & TdP \\
\hline $\begin{array}{l}\text { El-Battrawy et } \\
\text { al. [15] }\end{array}$ & 72 & Female & Nasal septoplasty & Angina pectoris & $\begin{array}{l}\text { T wave inversion I, aVL, } \\
\text { V1-6 }\end{array}$ & $\begin{array}{l}661 \\
\mathrm{~ms}\end{array}$ & \\
\hline $\begin{array}{l}\text { Cakıcı et al. } \\
{[16]}\end{array}$ & 67 & Female & Emotional & Dizziness, palpitations & Inverted T waves V3-6 & $\begin{array}{l}680 \\
\mathrm{~ms}\end{array}$ & VT \\
\hline Demir et al. [17] & 27 & Female & Endoscopic surgery & VF after surgery & $\begin{array}{l}\text { ST elevation I, aVL, } \\
\text { depression V3-6 }\end{array}$ & & VF \\
\hline $\begin{array}{l}\text { Watanabe et al. } \\
{[18]}\end{array}$ & 65 & Male & No & Dyspnea & Negative T wave V1-6 & $\begin{array}{l}693 \\
\mathrm{~ms}\end{array}$ & TdP-type VT \\
\hline $\begin{array}{l}\text { Rotondi et al. } \\
\text { [19] }\end{array}$ & 65 & Female & Emotional & Syncope & $\begin{array}{l}\text { Inverted T waves II, III, } \\
\text { aVF, V1-6 }\end{array}$ & $\begin{array}{l}671 \\
\mathrm{~ms}\end{array}$ & VT \\
\hline $\begin{array}{l}\text { Wakatsuki et } \\
\text { al. [20] }\end{array}$ & 81 & Male & $\begin{array}{l}\text { Pacemaker } \\
\text { implantation }\end{array}$ & Cardiac arrest due to VF & T wave inversion V3-6 & $\begin{array}{l}539 \\
\mathrm{~ms}\end{array}$ & VF \\
\hline $\begin{array}{l}\text { Caudron et al. } \\
\text { [21] }\end{array}$ & 34 & Female & Appendicectomy & Hemodynamic collapse & VF & & VF \\
\hline Williford [22] & 51 & Female & No & Syncope, chest pain & T wave inversion V4-6 & & $\begin{array}{l}\text { Polymorphic } \\
\text { VT }\end{array}$ \\
\hline Giusca [23] & 84 & Female & No & $\begin{array}{l}\text { Chest pain and sudden } \\
\text { cardiac death }\end{array}$ & T wave inversion V1-4 & & VF \\
\hline
\end{tabular}

TABLE 1: Characteristics of case reports included in this review presenting TdP, VF, and VT.

QTc: Corrected QT interval; VA: ventricular arrhythmia; VF: ventricular fibrillation; VT: ventricular tachycardia; TdP: torsades de pointes; PVC: premature ventricular contractions; ECG: electrocardiogram.

\section{Coronary vasospasm}

TTC usually has an overall long-term good prognosis with recovery in a matter of weeks [3]. However, not the usual course, some patients can have an increased risk for recurrent VA, which is related to recurrent coronary vasospasm [22]. We encountered two studies describing patients with coronary vasospasm leading to arrhythmic complications in TTC. The first one depicted a 51-year-old female with syncope, recurrent shortness of breath and palpitations, with polymorphic VT one year after the initial presentation [22]. The second one is of an 84-year-old woman who presented with SCD secondary to VF [23]. There was no emotional or physical stress on either one of the patients, but one had a personal history of tobacco use. Recurrence of TTC, especially presenting with VA in the setting of coronary-induced vasospasm, is not frequent. Women of young age with a history of anxiety and tobacco use have a significantly increased chance of developing myocardial damage and arrhythmias, even with a negative angiography [22]. This stunning of the myocardial tissue is temporary, and approximately only $28 \%$ of patients with TTC develop coronary artery spasm after provocation [3].

\section{Abnormal repolarization}

Streitner et al. studied the relationship between abnormal repolarization and fatal arrhythmias in 73 TTC 
patients at a medical center and collaborated with previously published cases from other authors. They analyzed the QTc values (corrected for heart rate) and measured T waves to assess repolarization parameters. They concluded that patients with malignant arrhythmias have, in general, lower ejection fraction than the average. They observed that the QTc showed increased values from day one to day three, and patients who developed TdP had slower heart rates [24]. We also identified this in some of the presented case reports $[13,14,18]$. The latter finding could indicate a direct relationship between abnormal depolarization and the genesis of VA. Song et al. studied 105 patients diagnosed with TTC who presented with or without QT prolongation. They performed daily ECG measuring QTc, ST-segment elevation, and T wave inversions. They found a higher incidence of VT/VF and SCD in patients with longer QTc [25]; TdP was also more frequent. The mortality rate was $7 \%$ during follow-up. They also believed that catecholamines play an essential role due to their effect in causing calcium overload in the myocardial cells. The action potential duration will determine the amount of calcium entering the myocytes; this can be increased in patients with long QT syndrome (LQTS) whose repolarization reserve appears reduced.

\section{Life-threatening arrhythmias, J wave, and fragmented QRS in Takotsubo cardiomyopathy}

Madias et al. reported an 8\% association between VA and TTC, and thus, they suggested to include TTC as one cause of acquired LQTS and a more significant risk factor for TdP [26]. Shimizu et al. evaluated the presence of J wave and fragmented QRS (fQRS) as a predictive measure of VA. They collected data of 31 patients and found the presence of J wave and fQRS only during the hyperacute phase of disease in $30 \%$ of patients; they concluded that J wave indicates a high risk of VA/cardiac death while fQRS predisposes to VF [27]. The presence of the J wave also showed high-risk mortality. They proposed ischemic electrical alterations and possible catecholamine effect as the J wave formation mechanism, while ischemic myocardial cells explain fQRS. This finding correlates with those of another study [1], in which the authors found that VF accounts for 30\% of the initial rhythm needing CPR and that presence of J wave on ECG was indicative of imminent VT.

Jesel et al. [28] studied a large cohort of 214 patients, and they found a 10.7\% incidence of LTA, which were associated with abnormal conduction and low ejection fractions. These patients presented with VT and TdP; all progressed to VF needing defibrillation. Most LTA occurred on the first day of admission, and 54\% of cases occurred out of the hospital and was the reason for admission. During long-term follow-up, the mortality rate was $25 \%$ for the entire population and $57 \%$ for the group with LTA. Repolarization changes and high adrenergic drive can prolong the QT and cause TdP [26]. In this study, 80\% of patients presented QTc values greater than $500 \mathrm{~ms}$ (mean of $507 \mathrm{~ms}$ ) [28]. The incidence of LTA is about $14 \%$ of TTC patients [29], 23\% mortality rate during hospitalization, and 30\% during long-term follow-up for the group with LTA [29].

\section{Common pathophysiological mechanisms of ventricular arrhythmias in Takotsubo cardiomyopathy}

Re-entry is the most common VA mechanism, especially in the presence of VT [1]. Based on areas of the myocardium affected by fibrosis and scarring, which could alter the electrical conductance, although TTC is a non-ischemic disease, the coexistence of regions with different electrical conductivities and myocardial edema might create a substrate for VA via re-entry [1]. Negative gadolinium enhancement studies suggest no scar formation and point toward triggered activity mechanism instead of re-entry [30,31].

A triggered activity can occur due to microvascular damage provoking repolarization anomalies. Furthermore, early afterdepolarization-induced triggered activity combined with excessive catecholamine activity could explain VT and TdP [1]. These early afterdepolarizations could present as ECG changes (affecting the T-U waves) [26]. The appearance of negative $\mathrm{T}$ waves in the acute stage of the disease may represent a more extensive myocardial damage and edema. Myocardial edema, in conjunction with prolonged QTc, increases the risk of VA and SCD [32,33]. Patients presenting with cardiac arrest had a higher mortality rate (40\%) during hospitalization. High levels of catecholamines could also alter the uptake of calcium into the myocardial cells causing them to display abnormal automaticity and mediate VA $[1,3,25,30]$.

\section{Takotsubo cardiomyopathy and anorexia nervosa as a substrate for ventricular arrhythmias}

Not much information is available about this topic in the literature. Ohwada et al. described the first three cases of an association between anorexia nervosa (AN) and TTC [34]. Only one patient had confirmed TTC, but they all shared clinical, ECG, and imaging findings consistent with TTC. They presented with hypoglycemia and electrolyte disturbances. Catecholamine levels were increased in two out of three cases, probably secondary to hypoglycemia. Two more studies describing patients with AN in the setting of TTC $[35,36]$ with similar clinical presentation except glucose levels were within the normal range for one of them [35], whereas the other one presented with hypoglycemia [36]. Prolongation of QTc and recurrent events of TdP occurred in one patient [35] and cardiogenic shock in the other [36]. Cardiac hypotrophy in AN might 
alter the duration of the action potential, and electrolyte anomalies may prolong the QTc contributing to VA development in these patients [35]. TTC usually occurs in postmenopausal women, and there is a possible role of estrogen deficiency in the development of complications in these patients. AN may induce hormonal changes in younger women making them more susceptible to TTC and complications such as VA [36,37].

Our review helped us summarize the most current and most accepted mechanisms that cause VA in patients with TTC (Figure 1) and has helped us understand a little more about the relationship between the clinical presentation, ECG findings, and clinical outcomes as morbidity and mortality.

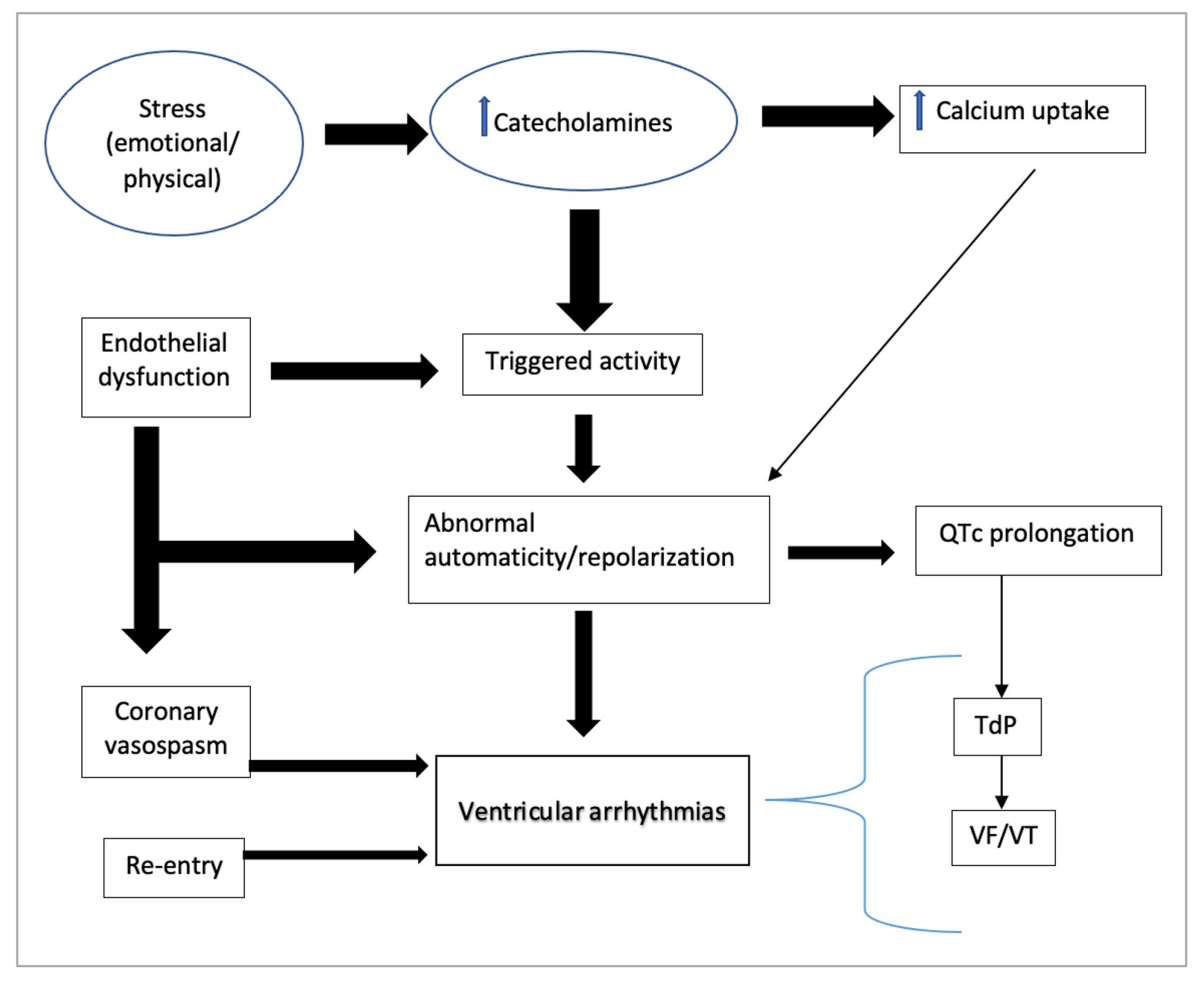

FIGURE 1: Pathogenic mechanisms of ventricular arrhythmias in
takotsubo cardiomiopathy.

VT: Ventricular tachycardia; VF: ventricular fibrillation; TdP: torsades de pointes; QTc: corrected QT interval.

\section{Limitations}

One limitation present in this review is that we only included studies from the year 2000 to present and fulltext access, possibly missing important information. Another is that we did not conduct a quality assessment.

\section{Conclusions}

Understanding the pathogenesis of TTC and its complications is a well-known challenge to clinicians around the world. In this context, VAs are present in many patients with TTC, and understanding how these two entities are related is very important. Their development's underlying pathophysiological mechanisms could help identify people at high risk of more severe cardiac events. This review aimed to summarize the most commonly proposed mechanisms provoking VA in patients affected by TTC and the effect on long-term prognosis in these patients. VA usually occurs in the acute phase of the disease and worsens the long-term prognosis of the disease. Depolarization anomalies such as T wave inversion and prolongation of QTc present in the early stage indicate a high risk of progression to severe and deadly arrhythmic events (TdP, VT, VF, and SCD). Catecholamine effect on myocardial cells and myocardial edema can create a substrate for the development of VA. Re-entry is the most common mechanism, but some studies argue it because of the lack of scar tissue in imaging studies. The latter fact points to triggered activity as one of the more accepted and probable theories; however, the exact mechanism remains uncertain.

In this review, we summarized all the possible mechanisms leading to VA and raised the awareness of a relationship between TTC and complications like VA. Also, we noticed AN could provide a substrate for the development of VA in patients with TTC, possibly due to a lack of protective effect of estrogen. Information 
about this topic is limited, and more studies are needed to clarify this relationship. The challenge for future scientists is to conduct more prospective studies and clinical trials assessing electrophysiological parameters in a more significant number of patients to stratify the risk and improve the prevention and management of LTA in TTC.

\section{Additional Information \\ Disclosures}

Conflicts of interest: In compliance with the ICMJE uniform disclosure form, all authors declare the following: Payment/services info: All authors have declared that no financial support was received from any organization for the submitted work. Financial relationships: All authors have declared that they have no financial relationships at present or within the previous three years with any organizations that might have an interest in the submitted work. Other relationships: All authors have declared that there are no other relationships or activities that could appear to have influenced the submitted work.

\section{References}

1. Möller C, Eitel C, Thiele H, Eitel I, Stiermaier T: Ventricular arrhythmias in patients with takotsubo syndrome. J Arrhythm. 2018, 34:369-375. 10.1002/joa3.12029

2. Y-Hassan S, Yamasaki K: History of takotsubo syndrome: is the syndrome really described as a disease entity first in 1990? Some inaccuracies. Int J Cardiol. 2013, 166:736-737. 10.1016/j.ijcard.2012.09.183

3. Roshanzamir S, Showkathali R: Takotsubo cardiomyopathy a short review. Curr Cardiol Rev. 2013, 9:191196. 10.2174/1573403x11309030003

4. Prasad A, Dangas G, Srinivasan M, Yu J, Gersh BJ, Mehran R, Stone GW: Incidence and angiographic characteristics of patients with apical ballooning syndrome (takotsubo/stress cardiomyopathy) in the HORIZONS-AMI trial: an analysis from a multicenter, international study of ST-elevation myocardial infarction. Catheter Cardiovasc Interv. 2014, 83:343-348. 10.1002/ccd.23441

5. Bybee KA, Prasad A, Barsness GW, et al.: Clinical characteristics and thrombolysis in myocardial infarction frame counts in women with transient left ventricular apical ballooning syndrome. Am J Cardiol. 2004, 94:343-346. 10.1016/j.amjcard.2004.04.030

6. Redfors B, Vedad R, Angeras O, et al.: Mortality in takotsubo syndrome is similar to mortality in myocardial infarction-a report from the SWEDEHEART registry. Int J Cardiol. 2015, 185:282-289. 10.1016/j.ijcard.2015.03.162

7. Y-Hassan S, Tornvall P: Epidemiology, pathogenesis, and management of takotsubo syndrome . Clin Auton Res. 2018, 28:53-65. 10.1007/s10286-017-0465-Z

8. Kawai S, Kitabatake A, Tomoike H, Takotsubo Cardiomyopathy Group: Guidelines for diagnosis of takotsubo (ampulla) cardiomyopathy. Circ J. 2007, 71:990-992. 10.1253/circj.71.990

9. Medina de Chazal H, Del Buono MG, Keyser-Marcus L, Ma L, Moeller FG, Berrocal D, Abbate A: Stress cardiomyopathy diagnosis and treatment: JACC State-of-the-Art Review. J Am Coll Cardiol. 2018, 72:19551971. 10.1016/j.jacc.2018.07.072

10. Migliore F, Zorzi A, Marra MP, et al.: Myocardial edema underlies dynamic T-wave inversion (Wellens' ECG pattern) in patients with reversible left ventricular dysfunction. Heart Rhythm. 2011, 8:1629-1634 10.1016/j.hrthm.2011.04.035

11. Sosnowska-Pasiarska B, Bąkowski D, Woronowicz-Chróściel A, Wożakowska-Kapłon B: Sudden cardiac arrest in takotsubo cardiomyopathy - a case study. Postepy Kardiol Interwencyinej. 2014, 10:110-113. 10.5114/pwki.2014.43517

12. Streitner F, Hamm K, Wittstein IS, et al.: Is abnormal myocardial repolarization associated with the occurrence of malignant tachyarrhythmias in takotsubo cardiomyopathy?. Cardiol J. 2013, 20:633-638. 10.5603/CJ.2013.0163

13. Ahn JH, Park SH, Shin WY, et al.: Long QT syndrome and torsade de pointes associated with takotsubo cardiomyopathy. J Korean Med Sci. 2011, 26:959-961. 10.3346/jkms.2011.26.7.959

14. Sasaki O, Nishioka T, Akima T, et al.: Association of takotsubo cardiomyopathy and long QT syndrome . Circ J. 2006, 70:1220-1222. 10.1253/circj.70.1220

15. El-Battrawy I, Behnes M, Borggrefe M, Akin I: Association of a congenital long QT syndrome type 1 with takotsubo cardiomyopathy. Clin Case Rep. 2016, 4:789-792. 10.1002/ccr3.567

16. Cakıcı M, Cetin M, Polat M, Süner A: Long QT-induced ventricular tachycardia associated with takotsubo cardiomyopathy. Turk Kardiyol Dern Ars. 2014, 42:71-75. 10.5543/tkda.2014.42272

17. Demir GG, Güler GB, Güler E, Güneş HM, Kızılırmak F: Sinus surgery complicated by ventricular fibrillation in a young patient: inverted (reverse) takotsubo cardiomyopathy. Turk Kardiyol Dern Ars. 2016, 44:418-422. 10.5543/tkda.2015.76128

18. Watanabe K, Noda M, Murakami T, et al.: Complete His-ventricular block, atrial flutter and ventricular tachycardia as arrhythmogenic activities in a patient with takotsubo cardiomyopathy. J Cardiol Cases. 2014, 10:208-212. 10.1016/j.jccase.2014.07.012

19. Rotondi F, Manganelli F, Capasso M, Lanzillo T, Bellizzi G, Sauro R: Recurrence of tako-tsubo syndrome, idiopathic dilated cardiomyopathy, and iterative ventricular tachycardia: just a fortuitous coincidence or a pathophysiological link?. Eur Rev Med Pharmacol Sci. 2013, 17:3117-3120.

20. Wakatsuki D, Asano T, Mase H, Kurata M, Suzuki H: A case of takotsubo cardiomyopathy developing ventricular fibrillation after a pacemaker implantation. J Cardiol Cases. 2020, 21:149-152. 10.1016/j.jccase.2019.12.002

21. Caudron J, Rey N, Dacher JN: Midventricular takotsubo cardiomyopathy associated with ventricular fibrillation during general anesthesia in a 34-year-old woman: insight from cardiac computed tomography and magnetic resonance imaging. Arch Cardiovasc Dis. 2012, 105:329-331. 10.1016/j.acvd.2011.04.016 
22. Williford NN, Mazur A, Rhodes T, Demetroulis E, Gebska MA: Coronary spasm and polymorphic ventricular tachycardia one year after takotsubo. Mayo Clin Proc Innov Qual Outcomes. 2019, 3:231-234.

10.1016/j.mayocpiqo.2019.01.001

23. Giusca S, Eisele T, Nunninger P, Münz B, Korosoglou G: Aborted sudden cardiac death in a female patient presenting with takotsubo-like cardiomyopathy due to epicardial coronary vasospasm. Case Rep Cardiol. 2017, 2017:1-4. 10.1155/2017/7875240

24. Streitner F, Hamm K, Wittstein IS, et al.: Is abnormal myocardial repolarization associated with the occurrence of malignant tachyarrhythmias in takotsubo cardiomyopathy?. Cardiol J. 2013, 20:633-638. 10.5603/CJ.2013.0163

25. Song BG, Chung SM, Kim SH, et al.: The QT prolongation and clinical features in patients with takotsubo cardiomyopathy: experiences of two tertiary cardiovascular centers. Anadolu Kardiyol Derg. 2014, 14:162169. 10.5152/akd.2013.4745

26. Madias C, Fitzgibbons TP, Alsheikh-Ali AA, et al.: Acquired long QT syndrome from stress cardiomyopathy is associated with ventricular arrhythmias and torsades de pointes. Heart Rhythm. 2011, 8:555-561. 10.1016/j.hrthm.2010.12.012

27. Shimizu M, Nishizaki M, Yamawake N, Fujii H, Sakurada H, Isobe M, Hiraoka M: J wave and fragmented QRS formation during the hyperacute phase in takotsubo cardiomyopathy. Circ J. 2014, 78:943-949. doi.org/10.1253/circj.CJ-13-1296

28. Jesel L, Berthon C, Messas N, et al.: Ventricular arrhythmias and sudden cardiac arrest in takotsubo cardiomyopathy: incidence, predictive factors, and clinical implications. Heart Rhythm. 2018, 15:1171-1178. 10.1016/j.hrthm.2018.04.002

29. El-Battrawy I, Lang S, Ansari U, et al.: Prevalence of malignant arrhythmia and sudden cardiac death in takotsubo syndrome and its management. Europace. 2018, 20:843-850. 10.1093/europace/eux073

30. Rotondi F, Manganelli F: Takotsubo cardiomyopathy and arrhythmic risk: the dark side of the moon . Eur Rev Med Pharmacol Sci. 2013, 17:105-111.

31. Syed FF, Asirvatham SJ, Francis J: Arrhythmia occurrence with takotsubo cardiomyopathy: a literature review. Europace. 2011, 13:780-788. 10.1093/europace/euq435

32. Gili S, Cammann VL, Schlossbauer SA, et al.: Cardiac arrest in takotsubo syndrome: results from the InterTAK Registry. Eur Heart J. 2019, 40:2142-2151. 10.1093/eurheartj/ehz170

33. Migliore F, Zorzi A, Marra MP, Iliceto S, Corrado D: Myocardial edema as a substrate of electrocardiographic abnormalities and life-threatening arrhythmias in reversible ventricular dysfunction of takotsubo cardiomyopathy: imaging evidence, presumed mechanisms, and implications for therapy. Heart Rhythm. 2015, 12:1867-1877. 10.1016/j.hrthm.2015.04.041

34. Ohwada R, Hotta M, Kimura H, et al.: Ampulla cardiomyopathy after hypoglycemia in three young female patients with anorexia nervosa. Intern Med. 2005, 44:228-233. 10.2169/internalmedicine.44.228

35. Rotondi F, Manganelli F, Lanzillo T, et al.: Tako-tsubo cardiomyopathy complicated by recurrent torsade de pointes in a patient with anorexia nervosa. Intern Med. 2010, 49:1133-1137. 10.2169/internalmedicine.49.3276

36. Volman MNM, Kate RWT, Tukkie R: Tako tsubo cardiomyopathy, presenting with cardiogenic shock in a 24year-old patient with anorexia nervosa. Neth J Med. 2011, 69:129-131.

37. Gupta S, Goyal P, Idrees S, Aggarwal S, Bajaj D, Mattana J: Association of endocrine conditions with takotsubo cardiomyopathy: a comprehensive review. J Am Heart Assoc. 2018, 7:129-131. 10.1161/JAHA.118.009003 